Uebergangsmetall-Methylen-Komplexe, XII. Zur reversiblen Protonierung einer elektronenreichen Metall-Metall-Bindung

von W.A. Herrmann, J. Plank und D. Riedel (Regensburg) (Eing den 22. Februar

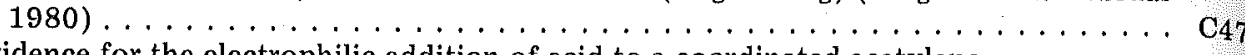
Evidence for the electrophilic addition of acid to a coordinated acetylene

by H.C. Clark and A.B. Goel (Guelph) (Rec'd September 12th, 1979)

Organogold chemistry. IV. Quinolyl- and phenanthridinyl-gold (I) compounds by L.G. Vaughan (Wilmington, DE) (Rec'd December 14 th, 1979) . . . . . . . . C56

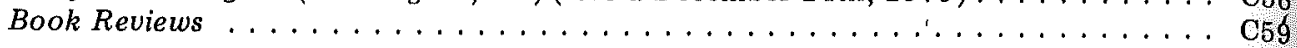

For Customers in the U.S.A. and Canada wishing additional bibliographic information on this and other Elsevier journals, please contact Elsevier North-Holland Inc., Journal Information Center, 52 Vanderbilt Avenue, New York, NY 10017. Tel.: (212) 867-9040.

This journal is cited by the following Abstracting/Indexing Services:

\author{
Automatic Subject Citation Alert \\ Chemical Abstracts \\ Chemie Information, Dokumentation (Berlin) \\ Current Abstracts of Chemistry and Index Chemicus \\ Current Contents, Physical, Chemical \& Earth Sciences \\ Science Citation Index
}

Journal of Organometallic Chemistry, 190 (1980) 107-116

c) Elsevier Sequoia S.A., Lausanne - Printed in The Netherlands

\section{NEW OBSERVATIONS ON THE METALATION OF NAPHTHALENE AND -ETHYLNAPHTHALENE BY POTASSIUM}

HUYNH-BA-GIA, R. JEROME and Ph. TEYSSIÉ

Laboratory of Macromolecular Chemistry and Organic Catalysis, University of Liège, Sart Tilman, 4000 Liège (Belgium)

(Received October 31st, 1979)

\section{Summary}

A stable dinegative ion can be formed when naphthalene is metalated by an excess of potassium in tetrahydrofuran at $25^{\circ} \mathrm{C}$; this previously unreported species in obtained only at naphthalene concentrations lower than $3 \times 10^{-2} \mathrm{~m} \mathrm{l}^{-1}$. In the case of $\beta$-ethylnaphthalene, the initial dianion is isomerized into a dihydronaphthalene monoanion carrying an extra-cyclic anion as a result of an intramolecular hydrogen transfer; this dianionic species can be formed at concentrations higher than $3 \times 10^{-2} \mathrm{~m} \mathrm{l}^{-1}$.

\section{Introduction}

Naphthalene is readily metalated by alkali metals in polar solvents such as tetrahydrofuran (THF). Either an anion-radical or a dianion can be formed, depending on the counter-ion, reagent concentration, time and temperature [1-4]. At room temperature or lower temperature, only a stable deep green radical-anion is formed in the presence of sodium [4]. Lithium is known to produce a radical-anion at $-80^{\circ} \mathrm{C}$, but in a second step and at naphthalene concentration lower than $0.5 \mathrm{~m} \mathrm{l}^{-1}$ a stable dianion is observed, which slowly decomposes at room temperature [2,5-7]. In the presence of potassium at $-80^{\circ} \mathrm{C}$ the exclusive formation of the radical-anion has been claimed [8]. Although we do not know of any experimental evidence for a dianion of naphthalene potassium or sodium in THF at room temperature, their transient participation in the Birch reduction in liquid ammonia has been invoked by some authors [9-11] but rejected by Smid [5].

Control of the naphthalene metalation is very important because the naphthalene radical-anion (NRA) and dianion are potential initiators of anionic polymerizations. The anion-radical is widely used in vinyl polymerization, the initiation taking place by transfer of the unpaired electron of the NRA to the 
unsaturated monomer $[1,4,12]$ (eq. 1).

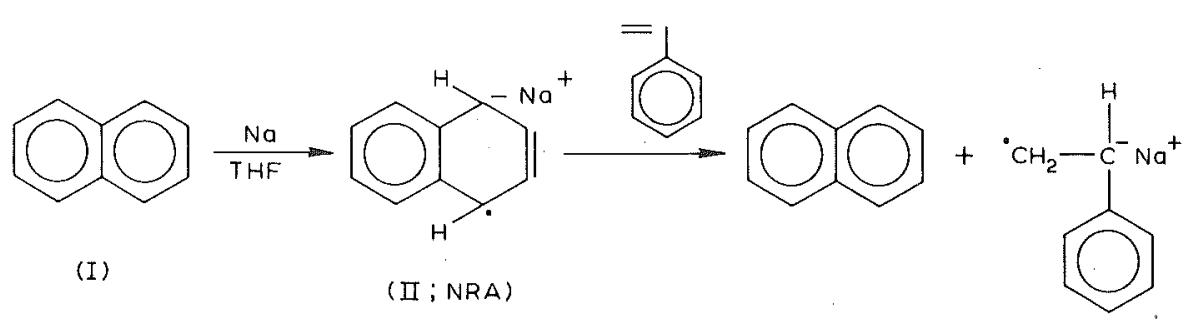

However, in the case of cyclic monomers such as cyclic ethers and siloxanes, the initiation proceeds differently and leads to a covalent bonding of the naphthalene to the growing chain $[1,12-14]$ (eq. 2).

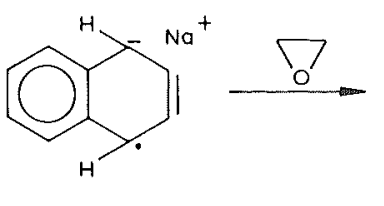

(II)

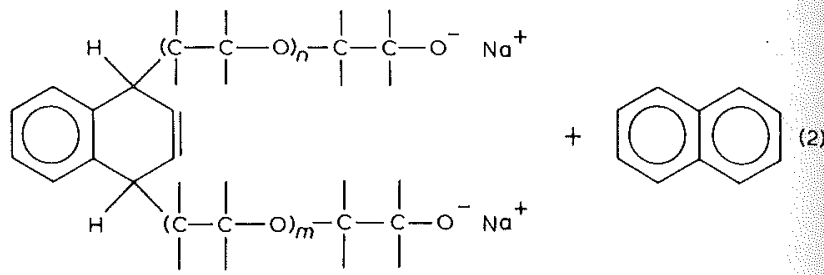

(P)
This mechanism has attracted attention as a potential way to prepare graft copolymers. For instance, ethylene oxide (EO) has been grafted onto polyvinylnaphthalene, and the initiation of two polyether chains per aromatic nucleus has been reported; however, the yield is limited with respect to the naphthalene units (eq. 2) and the metalation is complicated by a competing cleavage reaction $[15,16]$.

The only known naphthalene dianion ( $\mathrm{Li}$ ) has never been described as an initiator, but it is an excellent reagent for the synthesis of $\beta$-hydroxyacids [17]. If the existence and the stability of a potassium or sodium naphthalene dianion could be established, the polymer $(\mathrm{P})$ would be obtained without releasing half the naphthalene initiator as observed with the NRA (eq. 2). Furthermore, the attachment of a potassium or sodium naphthalene dianion to the end of a chain (i.e. PA) would open a very attractive pathway to prepare $\mathrm{PEO}$ based block copolymers with an original $\mathrm{PA}(\mathrm{PEO})_{2}$ star-shaped structure *. The lithium naphthalene dianion cannot be used for this purpose, as the organolithium compounds are unable to polymerize EO [18].

The aim of this work is to report a new aspect of the metalation of naphthalene and $\beta$-ethylnaphthalene by potassium in THF at RT, and especially the formation of a stable potassium dianion.

\section{Experimental}

THF (pure grade) was dried by refluxing over the benzophenone-sodium complex, and distilled under argon.

Anhydrous naphthalene and small clean pieces of potassium were placed into

\footnotetext{
* A series of four papers is to be published on this subject.
}

an argon-purged and flamed glass apparatus. After 3 cycles of evacuation and repressurization with argon, dried THF was introduced by distillation from a solution of oligomeric polystyryl potassium connected to the reaction vessel through a breakseal. The system was magnetically stirred during the metalation.

UV and visible spectrá were recorded on a Varian Techtron spectrophotometer, model 635 , using a $0.1 \mathrm{~mm}$ path quartz cell equipped with an inlet tube. The cell was argon-purged and flamed before being filled with the solution and before the final sealing. ${ }^{1} \mathrm{H}$ NMR spectra were obtained from a Varian $\mathrm{T} 60$ apparatus.

Titration. The carbanions were titrated potentiometrically by the Gilman's procedure (double titration) [19]. The content of hydroxyl end-groups was determined by back-titration with $\mathrm{NaOH}$ standard solution $(0.1 \mathrm{M})$ of the excess of phtalic anhydride $\left(3 \times 10^{-2} \mathrm{~m} \mathrm{l}^{-1}\right.$ in pyridine $)$ added to the dried polymer solution in THF. Accurately known amounts of polymer and phtalic anhydride were mixed and heated at $100^{\circ} \mathrm{C}$ for 4 hours before titration.

\section{Results and discussion}

Metalation of naphthalene by potassium in THF at room temperature

In the presence of potassium in $\mathrm{THF}$ at room temperature, naphthalene is first reduced to an anion-radical (deep green), but in a second step, new species are formed and a stable red-brown color is finally observed.

Titration at the end of the metalation (Table 1) shows the presence of two anions per naphthalene unit provided the naphthalene concentration is lower than $3 \times 10^{-2} \mathrm{~m} \mathrm{l}^{-1}$; beyond this limit the metalation falls to one carbanion per naphthalene. It is to be noted that the formation of the naphthalene dianion with lithium is similarly dependent on naphthalene concentration [2]. On the other hand, these anionic species are able to transfer one of their electrons to neutral naphthalene and the characteristic deep green color of the NRA is again observed. Similar behavior has been reported for the dianion of the naphthalene lithium (eq. 3) [5].

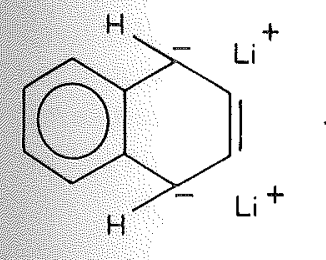<smiles>c1ccc2ccccc2c1</smiles>

THF<smiles>FC(F)(F)F</smiles>

(III)
The following reaction scheme is accordingly proposed for the metalation of naphthalene by potassium in THF at room temperature (eq. 4).

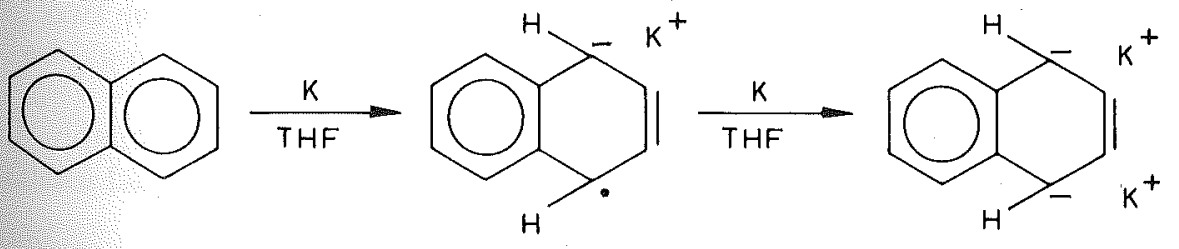


TABLE 1

NAPHTHALENE METALATION BY POTASSIUM IN THF AT ROOM TEMPERATURE

\begin{tabular}{lll}
\hline $\begin{array}{l}\text { Naphthalene } \\
\text { Concentration } \\
{[\mathrm{N}]\left(\mathrm{ml}^{-1}\right)}\end{array}$ & $\begin{array}{l}\text { Carbanions } \\
\text { Concentration } \\
{\left[\mathrm{C}^{-}\right]\left(\mathrm{ml}^{-1}\right)}\end{array}$ & $\frac{\left[\mathrm{C}^{-}\right]}{[\mathrm{N}]}$ \\
\hline $4.5 \times 10^{-3}$ & $0.9 \times 10^{-2}$ & 2.0 \\
$9.5 \times 10^{-3}$ & $1.9 \times 10^{-2}$ & 2.0 \\
$2.0 \times 10^{-2}$ & $4.0 \times 10^{-2}$ & 2.0 \\
$3.0 \times 10^{-2}$ & $5.9 \times 10^{-2}$ & 1.97 \\
$7.0 \times 10^{-2}$ & $1.1 \times 10^{-1}$ & 1.57 \\
$1.1 \times 10^{-1}$ & $1.1 \times 10^{-1}$ & 1.00 \\
\hline
\end{tabular}

$a^{a}$ Final constant values.

The metalation of naphthalene by potassium can also be studied by visible and ultra-violet spectrophotometry. After $6 \mathrm{~h}$ the absorption curve characteristic of the NRA [8] is observed (Fig. 1, A), whereas after $33 \mathrm{~h}$ the absorption is much modified and can be ascribed to the dianion of the naphthalene potassium derivative (Fig. 1, B). The assumed dianion is still stable at room temperature after $100 \mathrm{~h}$; however in the presence of an excess of neutral naphthalene, the absorption of the NRA is again observed. (Fig. 1, C). Once generated, the $\mathrm{K}$ dianion (IV) could react with the solvent and give rise to the three anionic species V, VI and VII (eq. 5).<smiles>[Y7]C1C=C[C+]([CH])c2ccccc21</smiles>

(IV)
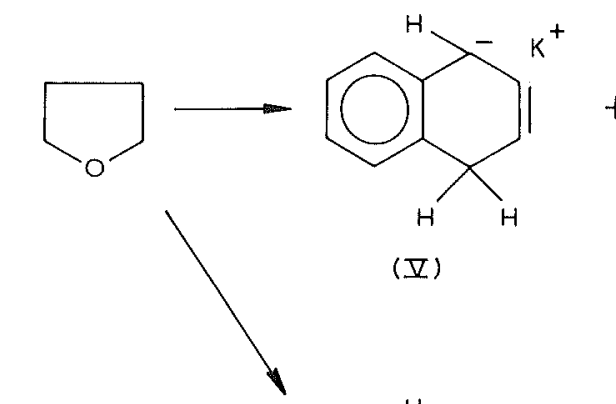

(Z)

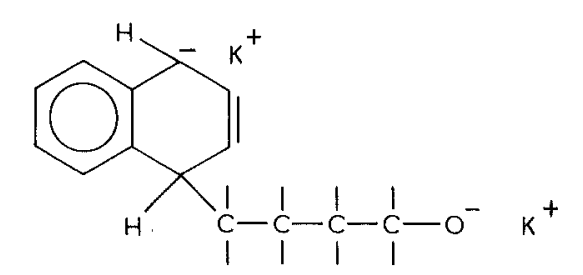

(घII)
However, it is well established that naphthalene monoanion (V, VII) is unable to transfer one electron to a neutral naphthalene molecule [5], while VI is quickly rearranged into ethylene and potassium-vinylalkoxide [20]. The two carbanions observed by titration per napthalene molecule must accordingly be attributed to the dianion IV itself.

The hydrolysis of the napththalene dianion must give rise to dihydronaphthalene, as described by eqs. 6 and 7, whereas it is well-known that equal

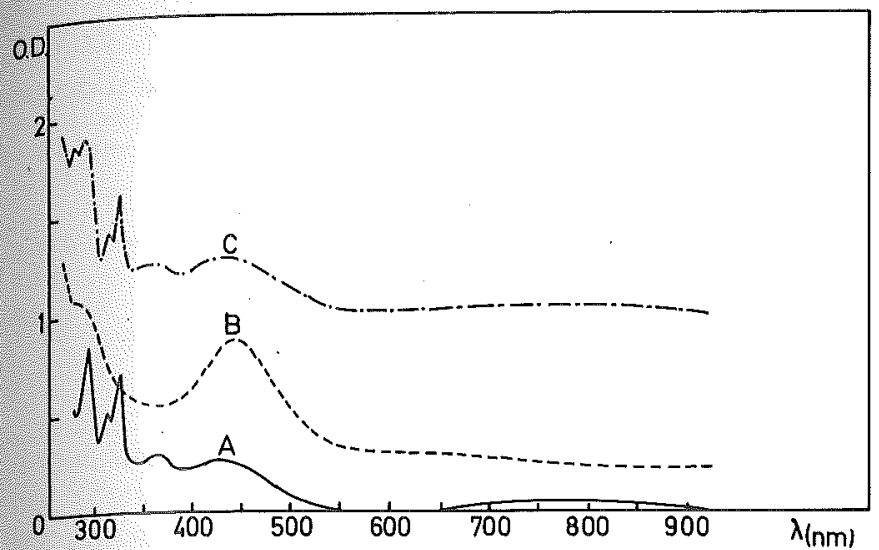

Fic, 1. Visible and UV spectra of: A, naphthalene metalated by $\mathrm{K}$ for $6 \mathrm{~h}\left(\mathrm{THF}, 25^{\circ} \mathrm{C}\right.$ ); B, ibid. for 33 and $100 \mathrm{~h}$ (O.D. values shifted upwards by 0.2 units); C, naphthalene metalated by $\mathrm{K}$ for $100 \mathrm{~h}$, with further ddition of neutral naphthalene (O.D. values shifted upwards by 1 unit).

amounts of naphthalene and dihydronaphthalene are obtained by the hydroly-

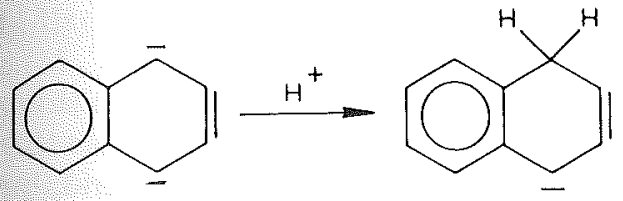<smiles>C1=CCc2ccccc2C1</smiles>
$\mathrm{H}^{+}$

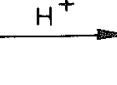

(5)

sis of NRA $[2,3,8,13]$. The hydrolysis products obtained from the assumed potassium naphthalene dianion have been studied by ${ }^{1} \mathrm{H}$ NMR spectroscopy; all the signals observed can be attributed to dihydronaphthalene protons $(\mathrm{Ta}-$ ble 2), and their assignment is in accordance with the results published by

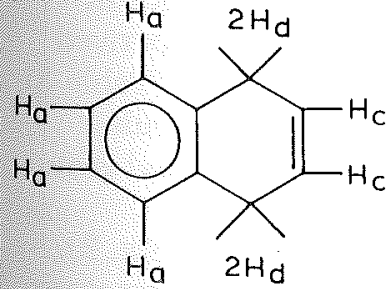

(VIII)<smiles>CC1=Cc2c(O)c([18OH])c([18OH])c(O)c2C(C)(C)C1(C)C</smiles>

(IX)

Zilkha [21] and Richards [2]. From the integration of the signals correspond- 
TABLE 2

$1_{\text {H NMR ANALYSIS OF THE HYDROLYSIS PRODUCTS FROM THE POTASSIUM NAPHTHALENE }}$ DIANION

\begin{tabular}{lll}
\hline Protons & $\begin{array}{l}\text { Chemical shift } \\
(\mathrm{ppm})^{a}\end{array}$ & \begin{tabular}{l} 
Multiplicity \\
\hline
\end{tabular} \\
\hline
\end{tabular}

\begin{tabular}{lll}
\hline $\mathrm{H}_{\mathrm{a}}$ & 7.15 & $\mathrm{~s}$ \\
$\mathrm{H}_{\mathrm{b}}$ & 6.3 & $\mathrm{~d}$ \\
$\mathrm{H}_{\mathrm{c}}$ & 5.9 & $\mathrm{~m}$ \\
$\mathrm{H}_{\mathrm{d}}$ & 3,3 & $\mathrm{~s}$ \\
$\mathrm{H}_{\mathrm{e}}$ & 2.5 & $\mathrm{~m}$ \\
\hline \\
\hline In ppm from tetramethylsilane as internal reference. ${ }^{b} \mathrm{~s}, \mathrm{~d}$ and m for singlet, doublet and multiplet,
\end{tabular}
respectively.

ing to $\mathrm{Hd}$ and He protons, the ratio between the forms VIII and IX was evaluated as being close to 3 .

In conclusion, complexes are formed in THF at RT between naphthalene and excess of alkali metals; the anion-radical only is formed with sodium, whereas dianions are observed with potassium and lithium. The potassium dianion is stable, in contrast to the lithium dinegative ion which has a half-life of about $11 \mathrm{~h}$ [22]. From a comparison of the standard potential $\epsilon\left(\mathrm{M}^{+}, \mathrm{M}\right)$ of the alkali metals, it is evident that the reducing power decreases from lithium $(\epsilon-3.02 \mathrm{~V})$ to potassium $(-2.92 \mathrm{~V})$ and again to sodium $(-2.71 \mathrm{~V})$. As the first reduction potential of naphthalene in THF is larger than the second, but just lower $(\Delta e 0.01 \mathrm{~V})$ than the standard potential of sodium [23], it is not surprizing that a naphthalene dinegative ion cannot be formed by this metal. The instability of the organolithium compounds in ether solvents is often men-

tioned in the literature [24], whereas the organopotassium derivatives are generally more stable [25]. This different behavior is probably related to the high solvation energy of the $\mathrm{Li}^{+}$ion, which is greater than that of the $\mathrm{K}^{+}$ion $[5,26]$; in THF, the $\mathrm{C}-\mathrm{Li}$ link is accordingly more ionic, and the attack on the ether solvent by the carbanion is favoured.

Metalation of $\beta$-ethylnaphthalene by potassium in THF at room temperature

To assess the influence of substitution on the metalation of naphthalene, $\beta$-ethylnaphthalene (EN) was studied as a model compound. Upon metalation under the same conditions, both naphthalene and $\beta$-ethylnaphthalene form a dianion as determined by titration, but two differences are to be noted. In contrast to the potassium naphthalene dianion, the dianionic species derived from EN can be formed at concentrations higher than $3 \times 10^{-2} \mathrm{~m} \mathrm{l}^{-1}$ (Table 3), and it is unable to transfer one electron to another naphthalene molecule. These differences are to be attributed to the participation of the $\beta$-ethyl group. in the metalation process.

The EN metalation has been analyzed by UV spectrophotometry (Fig. 2). The spectrum A obtained after 10 minutes presents the absorption characteristic of the naphthalene radical-anion (NRA) [8]. After $10 \mathrm{~h}$, a spectrum B corre sponding to the potassium naphthalene dianion (see Fig. 1, B) is observed, but changes gradually until the absorption at $600-650 \mathrm{~nm}$ disappears and a shoul-
TABLE3

METALATION OF $\beta$-ETHYLNAPHTHALENE (EN) BY K IN THF AT ROOM TEMPERATURE.

\begin{tabular}{llll}
$\begin{array}{l}\text { EN } \\
\left(\mathrm{m}^{-1}\right)\end{array}$ & $\begin{array}{l}\text { Time of metalation } \\
\text { (hours) }\end{array}$ & $\begin{array}{l}\text { [Carbanions] } \\
\left(\mathrm{ml}^{-1}\right)\end{array}$ & $\begin{array}{l}\text { No. of carbanions } \\
\text { per EN }\end{array}$ \\
\hline 0.160 & 120 & 0.32 & 2.0 \\
0.125 & 96 & 0.24 & 1.9 \\
0.016 & 33 & 0.03 & 2.0 \\
\hline
\end{tabular}

der at $280-290 \mathrm{~nm}$ is formed (spectrum C: $50 \mathrm{~h}$ of metalation). Spectrum $\mathrm{C}$ is not changed at all by the addition of pure naphthalene. It is noteworthy that the absorption at $435 \mathrm{~nm}$ (spectrum C) corresponds to the value reported for the dihydronaphthalene monoanion (DHNA) 433-435 $\mathrm{nm}$ [27].<smiles>C1=CCc2ccccc2C1</smiles>

DHNA

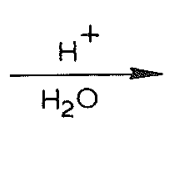

(<smiles>C1=CCCCC1</smiles>

Upon hydrolysis of DHNA, dihydronaphthalene (DHN) is formed, but this can be metalated again to give DHNA (eq. 8). Similarly, the anionic species derived from EN (Fig. 2, C) was hydrolyzed and the product after purification was metalated again by potassium under the same conditions; spectrum D (Fig. 2) so obtained is very similar to spectrum $\mathrm{C}$ except for a slight modification

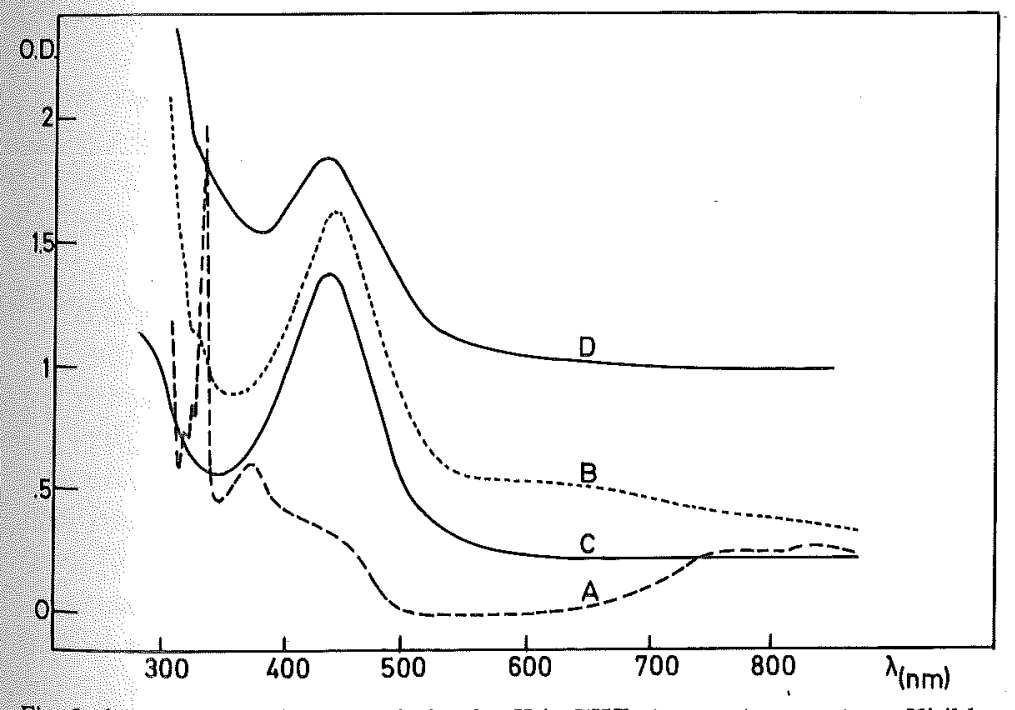

Fig. 2. $\beta$ ethylnaphthalene metalation by $K$ in THF at room temperature. Visible and UV spectra after: $A$, 10 minutes - NRA spectrum; B, 10 hours - naphthalene dianion spectrum (O.D. shifted upwards by 0.4 unit): $C, 50$ hours - (O.D. shifted upwards by 0.25 unit); D, Compound corresponding to spectrum $C$, water deactivated, purified and again metalated by $\mathrm{K}$ (O.D, shifted upwards by 1 unit). 
around $350 \mathrm{~nm}$. These observations suggest that the $\mathrm{EN}$ dinegative species includes a DHNA anion as well as a second, probably extra-cyclic, carbanion which can slightly modify the UV absorption of the former. To explain this participation of the ethyl group to the EN dianionic species, an intramolecular hydrogen transfer can be invoked (eqs. 9-12).<smiles>CCc1ccc2c(c1)CC=CC2</smiles>

(Z)

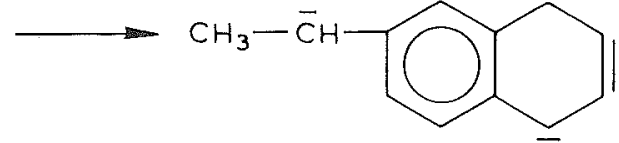

(XII)<smiles>C[CH-]c1ccc2c(c1)CC=CC2</smiles>

(XIII)<smiles>CCC1=CCc2ccccc2C1</smiles>
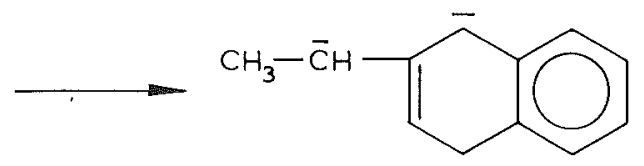

(XIV)

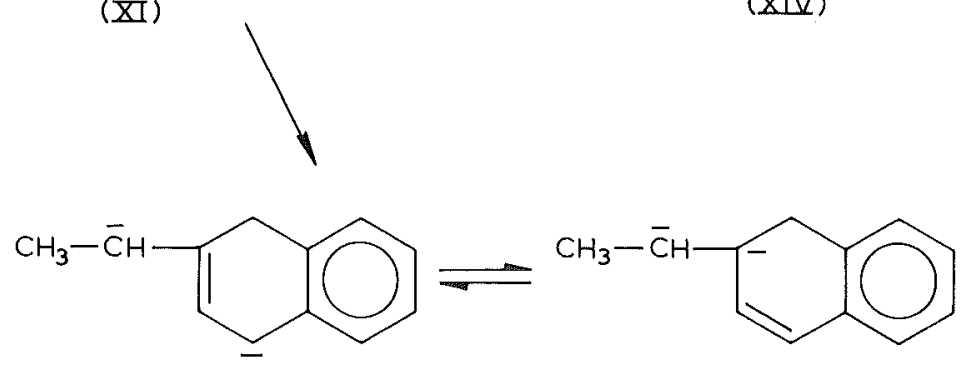

(XV)

The naphthalene-type dianion which is first formed during the metalation of EN (Fig. 2, B) can be represented by the forms X and XI depending on the presence of the ethyl group on the aromatic $(\mathrm{X})$ or the dihydronaphthalene (XI) ring. The isomerized EN dianions (XII-XVI and Fig. 2, C) were hydro lyzed and the resulting products studied by ${ }^{1} \mathrm{H}$ NMR. The resonances of the methyl and the alicyclic methylene groups are observed at 0.8 (triplet) and 2.2 ppm (quadruplet), respectively, which proves the existence of the form XI and favors species XV and XVI. This conclusion is in accord with the observations of Watanabe [6] and Rembaum [15]: the alkylation of the radical-anion or the anion derived from monosubstituted naphthalene takes exclusively place on the dihydronaphthalene nucleus. From the results of titration, UV and NMR measurements, the following mechanism can be proposed for EN metalation (eq. 13).

$$
\left(9 \bigcirc-\mathrm{CH}_{2}-\mathrm{CH}_{3} \frac{1 \mathrm{~K}}{\mathrm{THF}} \bigcirc \mathrm{CH}_{2}-\mathrm{CH}_{3} \frac{1 \mathrm{~K}}{\mathrm{THF}}=\right.
$$

$$
\text { (1) }
$$

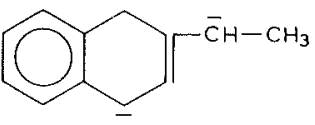

(XV)

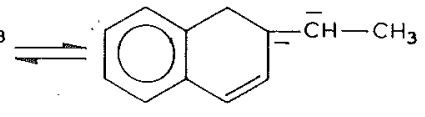

(XVI)
The compounds XV and XVI are similar to the dianion of a conjugated diene; they are highly stabilized by the presence of the aromatic nucleus and unable to transfer one electron to naphthalene [12]. The course of the metalation is determined by the formation of these conjugated and consequently low energy products. The dihydronaphthalene structure is, of course, unmodified by the hydrolysis of XV and XVI, and further metalation gives rise to a dihydronaphthalene monoanion (DHNA) (eq. 14) as indicated by Fig. 2, D.

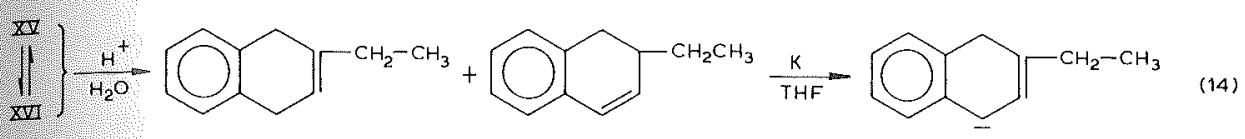

In conclusion, $\beta$-substitution of naphthalene has a marked influence on the course of the metalation by an excess of potassium in THF at RT. The naphthalene dianion is formed, but it is spontaneously isomerized into a dihydronaphthalene monoanion carrying an extra-cyclic anion on its dihydronaphthalene nucleus.

\section{Acknowledgements}

The authors are much indebted to Imperial Chemical Industries for effective support through the first European Joint Project, including a fellowship to H.B.G. They also thank Miss S. Boileau (University of Paris VI) for very helpful discussions.

\section{References}

1 N.G. Gaylord and S.S. Dixit, J. Polym. Sci., Macromolecular Rev., 8 (1974) 51.

2 F,J. Burgess, A.V. Cunliffe and D.H. Richards, Europ. Polym. J., 10 (1974) 645.

3 H.L. Hsieh, J. Organometal. Chem., 7 (1967) 1.

4 M. Szwarc, Nature, 178 (1956) 1168; M. Szware, M. Levy and R. Milkovich, J. Amer. Chem. Soc. 78 (1956) 2656.

5 J. Smid, J. Amer, Chem. Soc. 87 (1965) 655.

6 T. Fuita, K. Suga and S. Watanabe, Synthesis, (1972) 630.

1 J.C. Carnahan Jr. and W.D. Closson, J. Org. Chem., 37 (1972) 4469.

8 K.H.J. Buschow and G.J. Hoijtink, J. Chem. Phys., 40 (1964) 2501.

9 B.J. McLelland, Chem. Rev., 3 (1964) 301.

10 A.I. Shatenshtein, E.J. Petrov, M.I. Belousova, Org. Reactivity, 1 (1964) 191.

11 H. Smith, Organic Reactions in Liquid Ammonia, Wiley Interscience, New Yoxk, 1963.

12 M. Morton and L.J. Fetters, Rubber Chem. Techn., 48 (1975) 359.

13 D.H. Richards and M. Szware, Trans. Faraday Soc., 55 (1959) 1644.

14 K.S. Kazanskii, A.A. Solovy anov and S.G. Entelis, Europ. Pol. J., 7 (1971) 1421. 
15 A, Rembaum, J. Moacanin and E. Cuddihy, J. Polym, Sci. C, 4 (1964) 529. 16 G. Goutiere and J. Gole, Bull. Soc. Chim. France, 31 (1965) 153.

17 S. Watanabe, K. Suga, T. Fujita and K. Fujiyoshi, Israel J. Chem, 8 (1970) 731

18 E.C. Steiner, R R. Pelletier and R O. Trucks, J. Amer. Chem Soc, 86 (1904) 4078 .

E.C. Steiner, R.R. Pelletler.

19 H. Glman and A.H, Hauben, J. Amer, Chem. Soc., 66 (1944) 1515.

20 R.B. Bates, L.M. Kroposki and D.E, Potter, J. Org. Chem. 37 (1972) 560

22 G. Henrici-Olivé and S. Olivé, Z. Phys. Chem., 42 (1964) 145; 43 (1964) 327, 334, 340.

23 J. Hoijtink, E. De Boer, P.H. Van der Maij and W.P. Weyland, Rec. Trav. Chim. Pays-Bas, 75 (1956) 487.

24 B.J. Wakefield, The chemistry of organolithium compound, Pergamon Press, New York, 1974 25 A. Sami, M. Levy and M. Szware, J. Chem. Soc., (1962) 362.

26 J.W. Burley and R.N. Young, J. Chem. Soc. B, (1971) 1018.

27 S. Bank and B. Bockrath, J, Amer, Chem, Soc, 93 (1971) 430
Jounal of Organometallic Chemistry, 190 (1980) 117-128

Elsevier Sequoia S.A., Lausanne - Printed in The Netherlands

\section{PHOTOLYSIS OF ORGANOPOLYSILANES. PHOTOCHEMICAL FORMATION AND REACTIONS OF 1-TRIMETHYLSILYL-1-PHENYL- 1.SILACYCLOPROPENE DERIVATIVES *}

MITSUO ISHIKAWA, KEN-ICHI NAKAGAWA and MAKOTO KUMADA

Department of Synthetic Chemistry, Faculty of Engineering, Kyoto University, Kyoto 606 (Japan)

(Received September 6th, 1979)

\section{Summary}

The photolysis of tris(trimethylsilyl)phenylsilane (I) in the presence of 1-hexyne, 3,3-dimethyl-1-butyne, trimethylsilylacetylene, 3-hexyne, 1-trimethylsilylpropyne, 1,2-bis(trimethylsilyl)acetylene and 2,2,5,5-tetramethyl3 -hexyne afforded the respective silacyclopropenes. The silacyclopropenes produced from monosubstituted acetylenes underwent photochemical isomerization to give disilanylacetylene derivatives, via a 1,2-hydrogen shift in the silacyclopropene ring. Irradiation of I in the presence of 3-hexyne, 1-trimethylsilylpropyne or 2,2,5,5-tetramethyl-3-hexyne gave the corresponding silacyclopropenes which could be isolated by preparative GLC. The silacyclopropene from 1,2 bis(trimethylsilyl)acetylene, however, readily underwent thermal rearrangement to give [bis(trimethylsilyl)phenylsilyl] trimethylsilylacetylene via a 1,2-trimethylsilyl shift. This type of rearrangement was also found in the photochemical process.

\section{Introduction}

The chemistry of silacyclopropenes has recently been developed by several research groups, and some of the silacyclopropenes have been isolated and characterized [ $1-5]$. However, the chemical behavior of the silacyclopropenes is not as well understood as that of the cyclopropenes [6-10].

In 1970 , we found that photolysis of cyclic and acyclic organopolysilanes affords a convenient route to divalent organosilicon intermediates [11]. We also reported that photochemically generated dimethylsilylene and methylphenylsilylene react with various olefins to give the silacyclopropanes $[12,13]$.

* For a preliminary communication see ref, 4. 